\title{
MECHANICAL PROPERTIES OF ZEK100 Mg ALLOY
}

By:

Yuntao Li, Bachelor of Mechanical Engineering,Toronto, 2015

\author{
A MRP \\ presented to Ryerson University
}

\author{
in partial fulfillment of the \\ requirments for the degree of \\ Master of Engineering \\ in the Program of \\ Mechanical and Industrial Engineering
}

Toronto, Ontario,Canada, 2017

(C) Yuntao Li 2017 


\section{AUTHOR'S DECLARATION FOR ELECTRONIC SUBMISSION OF A MRP}

I hereby declare that I am the sole author of this MRP. This is a true copy of the MRP, including any required final revisions, as accepted by my examiners.

I authorize Ryerson University to lend this MRP to other institutions or individuals for the purpose of scholarly research.

I further authorize Ryerson University to reproduce this MRP by photocopying or by other means, in total or in part, at the request of other institutions or individuals for the purpose of scholarly research.

I understand that my MRP may be made electronically available to the public. 
Mechanical Properties of ZEK100 Mg Alloy

Master of Engineering, 2017

Yuntao Li

Mechanical and Industrial Engineering

Ryerson University

Low rare-earth containing magnesium $(\mathrm{Mg})$ alloys are considered lightweight structure materials and are wildely used in automotive and aerospace industry. Tensile and fatigue behaviors are two important mechanical properties of metallic alloys. This research focused on the tensile and fatigue properties of ZEK100 Mg alloys. Microstructure of ZEK100 alloy contained equiaxed grains and exhibited relatively weaker texture compared with other RE-free Mg alloys. During tensile test, as the strain rate increased, yield stress, ultimate tensile strength and hardening capacity increased, but the elongation decreased. Strain rate was found to influence tensile properties of ZEK100 Mg alloy. The stress controlled fatigue test showed that as the stress ratio increased, the stress amplitude and the fatigue life both decreased. Fatigue crack was observed to initiate from specimen surface, and crack propagation was characterized by fatigue striations.

Keywords: Mg alloys, lightweight, fatigue, RE elements. 


\section{Table of Contents}

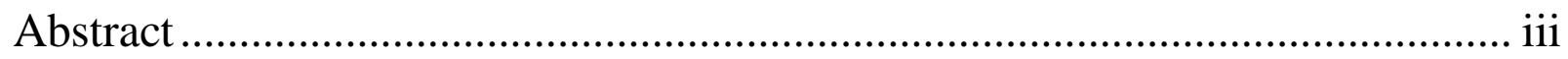

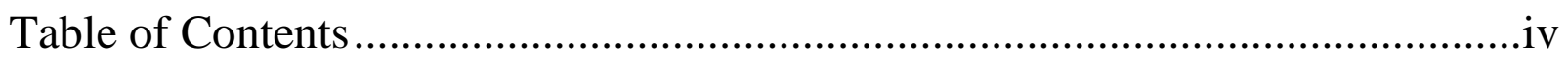

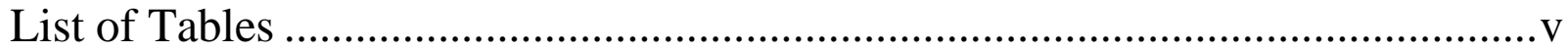

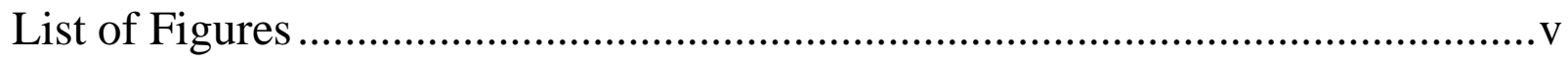

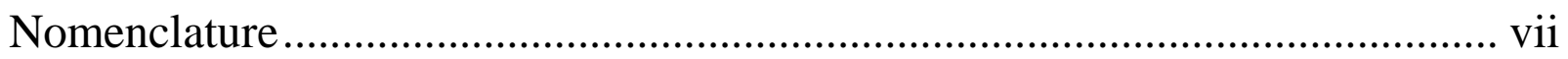

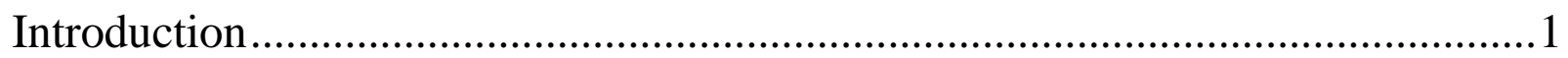

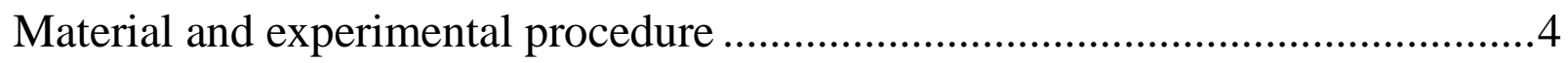

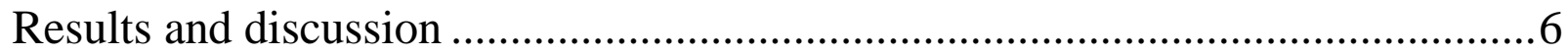

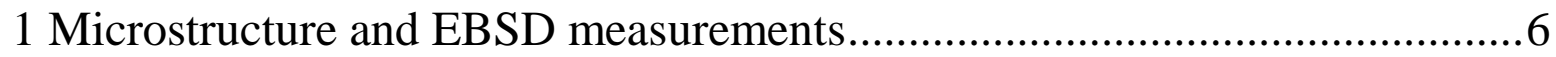

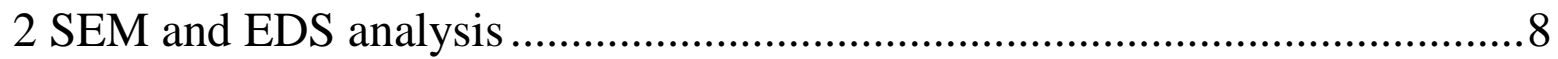

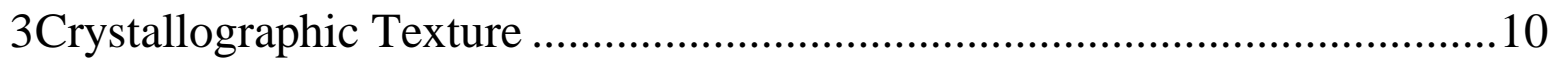

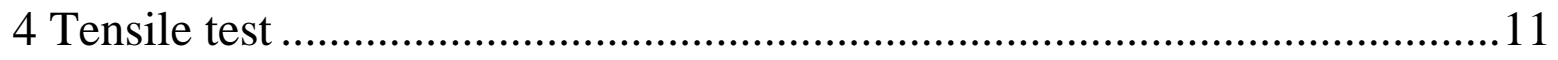

5 Stress-controlled fatigue test..................................................................13

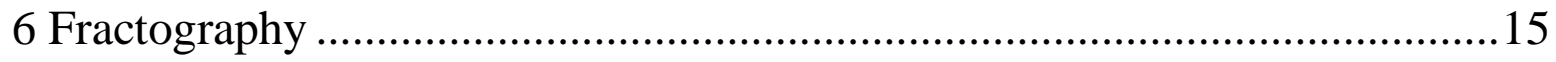

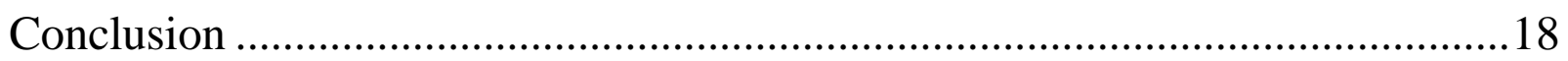

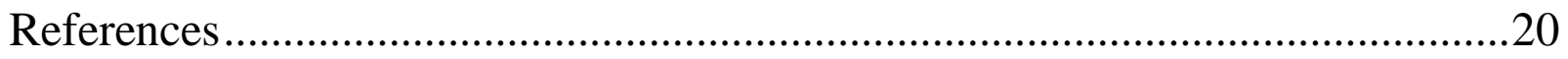




\section{List of Tables}

Table 1 Chemical composition of ZEK100 Mg alloy (wt.\%) .......................................4

Table 2 Tensile properties of ZEK100 alloys obtained at two different strain rate at room

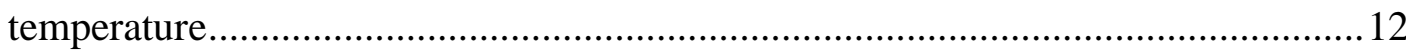

Table 3 High cycle fatigue parameters obtained at different stress ratio for the rolled ZEK100 Mg. 14

\section{List of Figures}

Fig.1. Microstructure of casted AM50 sample ..................................................... 2

Fig.2.Microstructure of extruded AZ31 (a) Microstructure near top surface, (b) Microstructure in the transition area which blow the top layer, (c) Microstructure of the center layer, (d) Microstructure at the near bottom area..................................2

Fig.3. Fatigue test specimen geometry and dimensions (in $\mathrm{mm}$ ) for the ZEK100 Mg alloy.5

Fig.4. Optical micrograph of the rolled ZEK100 Mg alloy, where RD stands for the rolling direction and ND indicates the normal

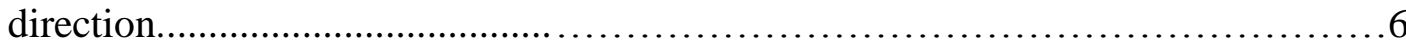

Fig.5. Normal-projected EBSD (a) orientation map of the rolled ZEK100 Mg alloy, (b) band contrast (BC) map of the rolled ZEK100 Mg alloy, where RD stands for the rolling direction and ND indicates the normal direction. ...........................................

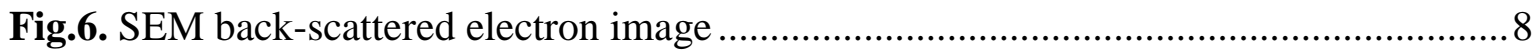

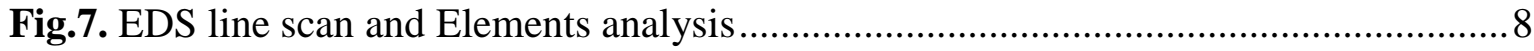

Fig.8. Point Scan of the ZEK100 Mg alloy .............................................................. 9

Fig.9. (0001), (10 $\overline{1} 0)$ and $(10 \overline{1} 1)$ pole figures of the rolled ZEK100 Mg alloy, where RD stands for the rolling direction, TD for the transverse direction, and ND for the normal direction.

Fig.10. Relationship of true stress vs. true strain for ZEK100 under two strain rate.........11

Fig.11. Mechanical properties of ZEK100 under strain rate of $1 \times 10^{-2} s^{-1}$ and $1 \times 10^{-2} s^{-4}$ : (a) Yield Stress; (b) Ultimate tensile strength; (c) Hardening capacity; (d) Elongation.

Fig.12. S-N curve for ZEK100 Mg alloy with different stress ratio. 13

Fig.13. SEM Microstructure of overall fracture surface of the specimens fatigued at Stress ratio $R=0.5$, Stress amplitude $60 \mathrm{MPa}$ (a) overall fracture surface, (b) initiation area. 
Fig.14. SEM Microstructure of overall fracture surface of the specimens fatigued at Stress ratio $\mathrm{R}=0.5$, Stress amplitude $60 \mathrm{MPa}$ (a) overall fracture surface with slected crack propagation zone, (b)crack propagation area ........................................... 16

Fig.15. SEM Microstructure of fast crack area for $\mathrm{Mg} \mathrm{ZEK} 100$ fatigued at Stress ratio $\mathrm{R}=0.5$, Stress amplitude $60 \mathrm{MPa}$ 


\section{Nomenclature}

\begin{tabular}{|c|c|}
\hline Abbreviation & Full name \\
\hline Mg & Magnesium \\
\hline Nd & Neodymium \\
\hline Zn & Zinc \\
\hline Zr & Zirconium \\
\hline OM & Optical Microscopy \\
\hline SEM & Scanning Electron Microscope \\
\hline DRX & Dynamic Recrystallization \\
\hline EBSD & Electron Backscattered Diffraction \\
\hline EDS & X-ray spectroscopy \\
\hline XRD & X-ray diffractometer \\
\hline RD & Rolling Direction \\
\hline ND & Normal Direction \\
\hline TD & Transverse Direction \\
\hline LD & Loading Direction \\
\hline HC & Hardening Capacity \\
\hline UTS & Ultimate tensile strength \\
\hline HCF & High cycle fatigue \\
\hline LCF & Low Cycle Fatigue \\
\hline RE & Rare earth elements \\
\hline TEM & Yield Strength \\
\hline YS & \\
\hline & \\
\hline
\end{tabular}




\section{Introduction}

$\mathrm{Mg}$ is one of the lightest structural materials and was found to be one of the eighth most abundant element on earth, constituting $2 \%$ of the total mass of the earth's crust [7]. Mg alloys are widely used in automotive and aerospace industry because of their low density, high strength to weight ratio and good mechanical properties [1,6,7]. Mg alloys are also used as biodegradable implants due to their good biocompatibility and biodegradability [8]. The highly recyclable $\mathrm{Mg}$ is currently used for cars and light truck vehicles components including ultra-lightweight car engines, engine valve covers, instrument panels, steering components, radiator supports, door and lift gate inners, seat structures and wheels [9]. Developing Mg alloys for practical industrial applications have tremendously increased worldwide during the past two decades [8]. However, they have poor corrosion resistance and limited room temperature(RT) formability [9, 6]. The most commonly used Mg alloys are cast magnesium and extruded magnesium alloy. Since the normal die casting would cause gas porosity and limit the mechanical properties of magnesium alloys, extruded and rolled magnesium alloys were developed to fit for more industrial requirements [7]. Some of the most commercial Mg alloys are listed in Table.1 [10]:

\begin{tabular}{|l|l|}
\hline AZ series & $(\mathrm{Mg}-\mathrm{Al}-\mathrm{Zn})$ \\
\hline AM series & $(\mathrm{Mg}-\mathrm{Al}-\mathrm{Mn})$ \\
\hline AE series & $(\mathrm{Mg}-\mathrm{Al}-\mathrm{RE})$ \\
\hline EZ series & $(\mathrm{Mg}-\mathrm{RE}-\mathrm{Zn})$ \\
\hline ZK series & $(\mathrm{Mg}-\mathrm{Zn}-\mathrm{Zr})$ \\
\hline WE series & $(\mathrm{Mg}-\mathrm{RE}-\mathrm{Zr})$ \\
\hline
\end{tabular}

The typical microstructure of cast magnesium alloys usually has eutectic structure, this structure contains main $\alpha$ - phase and second phase $\beta$ - phase, as shown in Fig.1. 


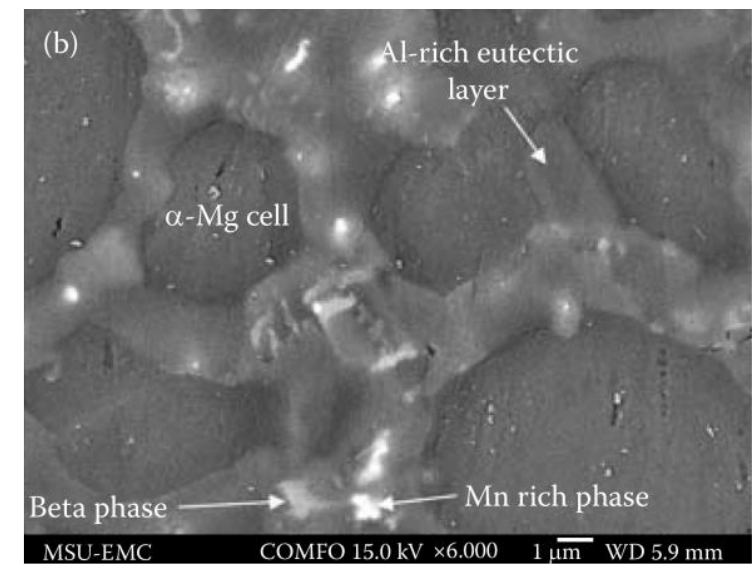

Fig.1 Microstructure of casted AM50 sample

Extruded magnesium alloys shows three layers. The top and bottom layers of the extruded plate are full of large grains, where the center of the extrude plate contains small grains with average size [7]. The fine and equiaxed grains in the center layer could provide good mechanical properties, such as higher strength and ductility [7]. The typical microstructure of extrude magnesium alloys was shown in Fig.2.
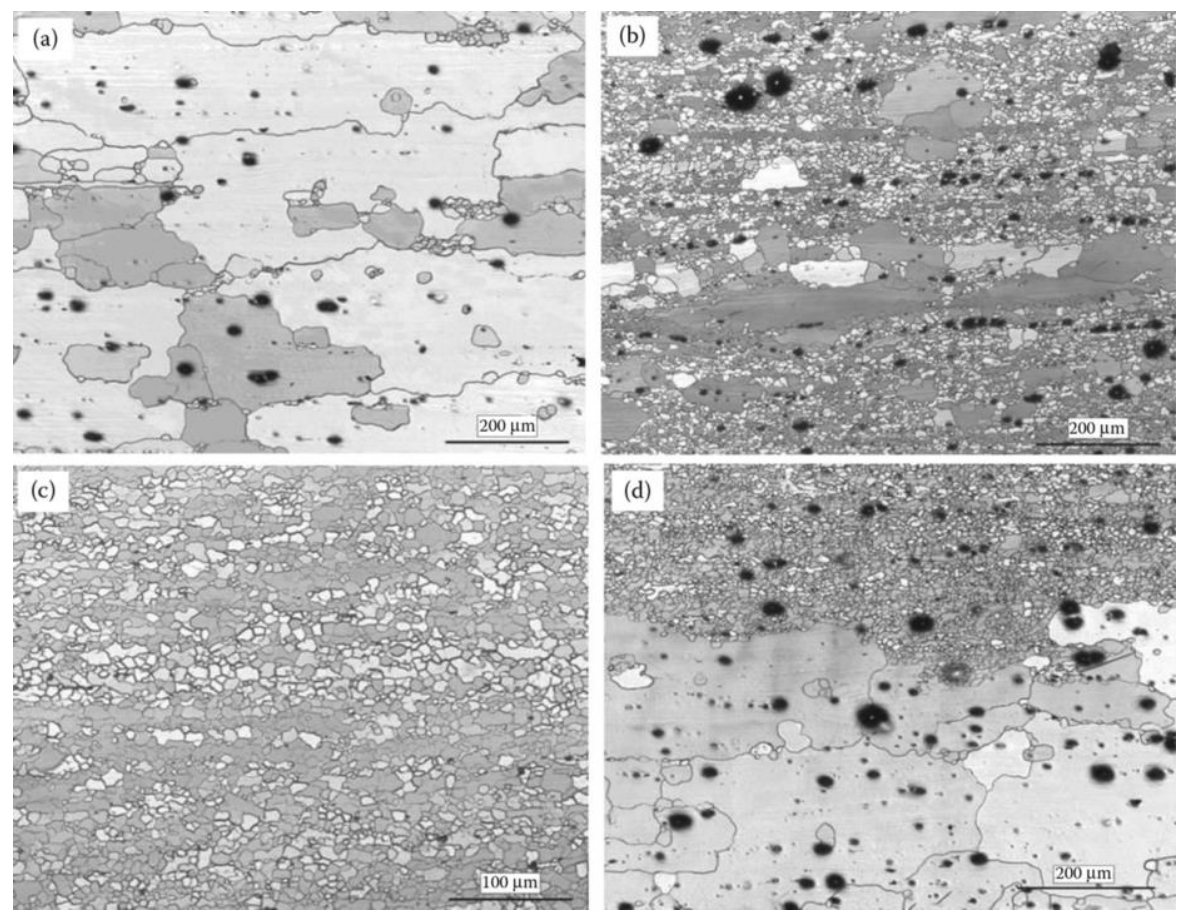

Fig.2 Microstructure of extruded AZ31 (a) Microstructure near top surface, (b) Microstructure in the transition area which blow the top layer, (c) Microstructure of the center layer, (d) Microstructure at the near bottom area [7,11]. 
To avoid the disadvantages of cast and extruded magnesium alloys, RE-containing $\mathrm{Mg}$ alloys were developed and studied in recent years. Both the tension-compression yield asymmetry and roomtemperature formability could be effectively improved by adding metallic elements, especially rare-earth (RE) elements due to their tendency to induce texture randomization during hot processes (e.g., extrusion or rolling), which leads to the decrease of texture intensities and the activation of basal slip [11-13]. Thus, it is necessary to explore the effect of rare-earth alloying on the mechanical properties and deformation mechanisms of $\mathrm{Mg}$ alloys with respect to their microstructure, crystallographic texture, cyclic stress-strain responses and pseudo-elastic behavior. Although the addition of RE elements promises greatly improved mechanical properties, it is still unclear to what extent RE-containing Mg alloys would behave differently from RE-free alloys and in which aspects. This research focused on rolled ZEK1000-O Mg alloys and analyzed the mechanical properties of this newly developed alloy. 


\section{Material and experimental procedure}

The investigated material in this study was rolled ZEK100 Mg alloy sheet with 3mm thickness. The alloy was in the annealed condition designated as ZEK100-O which means the annealing was done at $500^{\circ} \mathrm{C}$ for $15 \mathrm{~min}$ in electrical oven $[14,15]$. The chemical composition of the alloy is given in Table 1.

Table 1 Chemical composition of ZEK100 Mg alloy sheet (wt.\%).

\begin{tabular}{llllll}
\hline Base material & Zn & Zr & Nd & Mn & Mg \\
\hline ZEK100 & 1.3 & 0.25 & 0.2 & 0.01 & Bal. \\
\hline
\end{tabular}

For commercial $\mathrm{Mg}$ alloys, zinc(Zn) is commonly used for improvement of strength at ambient temperatures, [16] zirconium $(\mathrm{Zr})$ is used as grain refiner and Neodymium(Nd) is rare earth element. Microstructure was observed using optical microscope $(\mathrm{OM})$ equipped with an image analysis system, and a scanning electron microscope(SEM) JSM-6380LV along with an Oxford energy dispersive X-ray spectroscopy(EDS) system. For microstructure observations, samples were accomplished by following standard metallographic techniques, and microstructural features were revealed using an etchant of acetic picral solution (i.e., $4.2 \mathrm{~g}$ picric acid, $10 \mathrm{ml}$ acetic acid, $10 \mathrm{ml}$ $\mathrm{H}_{2} \mathrm{O}$ and $70 \mathrm{ml}$ ethanol). Specimens for the EBSD examinations were first mechanically polished and then electro-polished in an electrolyte of $10 \mathrm{ml}$ nitric acid and $40 \mathrm{ml}$ ethanol for about $30 \mathrm{~s}$ at $20 \mathrm{~V}$ under room temperature. Crystallographic texture was determined with a PANalytical X-ray diffractometer (XRD) with $\mathrm{Cu} \mathrm{K}_{\alpha}$ radiation at $45 \mathrm{kV}$ and $40 \mathrm{~mA}$ in a back-reflection mode by measuring partial pole figures (i.e., ranging between $\Psi=0^{\circ}$ and $75^{\circ}$ ). Texture data was evaluated using Matlab-based MTEX software [17]. 
Tensile tests were performed by using United tensile machine with a sample gauge length of $25 \mathrm{~mm}$ at strain rate of $1 \times 10^{-2} s^{-1}$ and $1 \times 10^{-2} s^{-4}$ at room temperature. Stress controlled fatigue tests were conducted using a computerized INSTRON 8801 fatigue testing system at room temperature. The size of tested dog bone shaped samples was shown in Fig.3. The fatigue samples were machined with the loading direction along with the rolling direction (RD). Two samples were tested at each stress level to make sure of the reproducibility of the results. Fracture surfaces of fatigued samples were examined by SEM to identify different features such as fatigue initiation sites and propagation mechanisms.

140

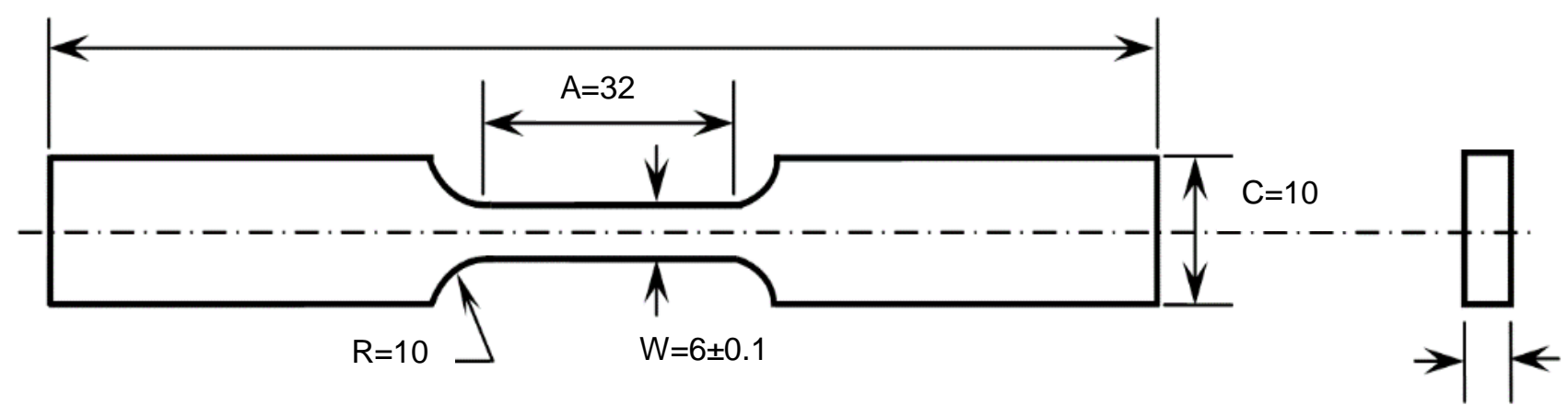

Fig.3 Fatigue test specimen geometry and dimensions (in mm) for the ZEK100 Mg alloy 


\section{Results and discussion}

1 Microstructure and EBSD measurements

Microstructure of rolled ZEK100 alloy was shown in Fig.2, where the two directions were indicated (RD: rolling direction; ND: normal direction). Most of the grains from Fig.4 were characterized as equiaxed under qusai-uniform distribution. This phenomenon was due to dynamic recrystallization (DRX) during rolling and followed annealing treatment. Studies about as cast ZEK100 showed microstructure of cold work could cause a lot of twins appear in micrograph [1]. Fig.4 indicated that after annealing, the pre-existent twins disappeared and new equiaxed grains were formed. And black dots in Fig.4 indicate the small fraction of randomly distributed secondphase precipitates. The formation of equiaxed grains were due to the addition of RE element $\mathrm{Nd}$ and $\mathrm{Zr}$, as reported by other researches [4], where the extruded $\mathrm{GW} 103 \mathrm{~K} \mathrm{Mg}$ alloy exhibited smaller grain size due to RE elements resist grain growth.

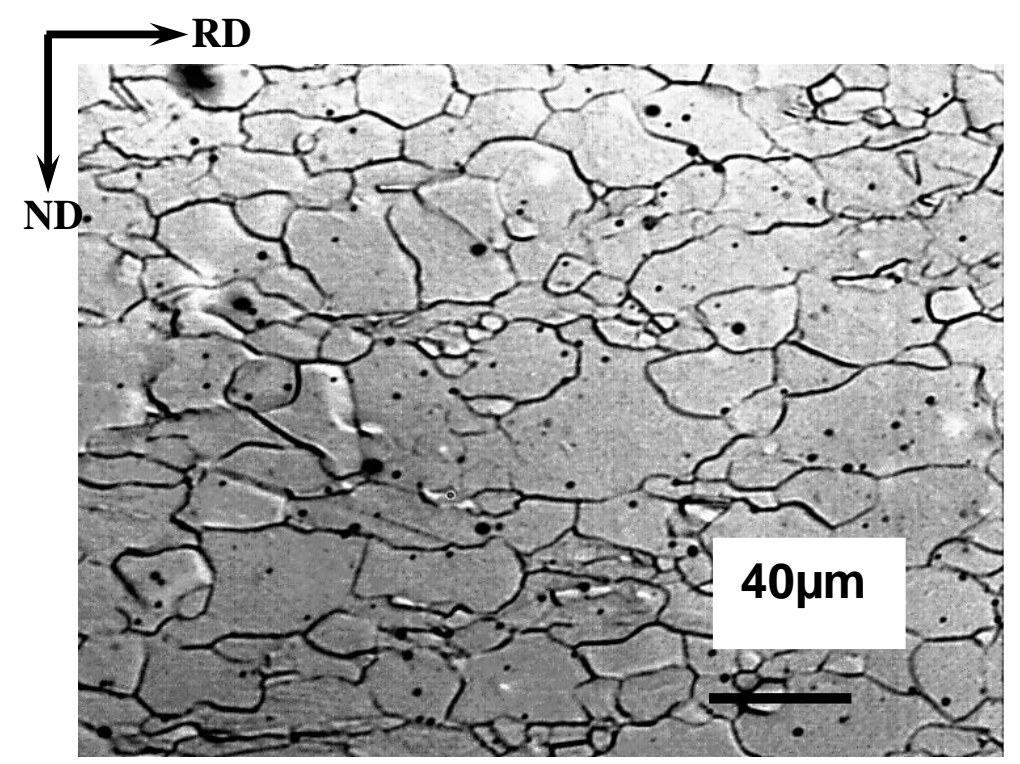

Fig.4 Optical micrograph of the rolled ZEK100 Mg alloy, where RD stands for the rolling direction and ND indicates the normal direction. 
Another feature could be seen from Fig.5, the standard color key provided that the majority grains on the RD-ND planes were oriented with c-axis perpendicular to the RD while the basal planes were parallel to the RD. This observation was commonly reported by other studies about rolled and extruded ZEK100 Mg alloys [18,19].
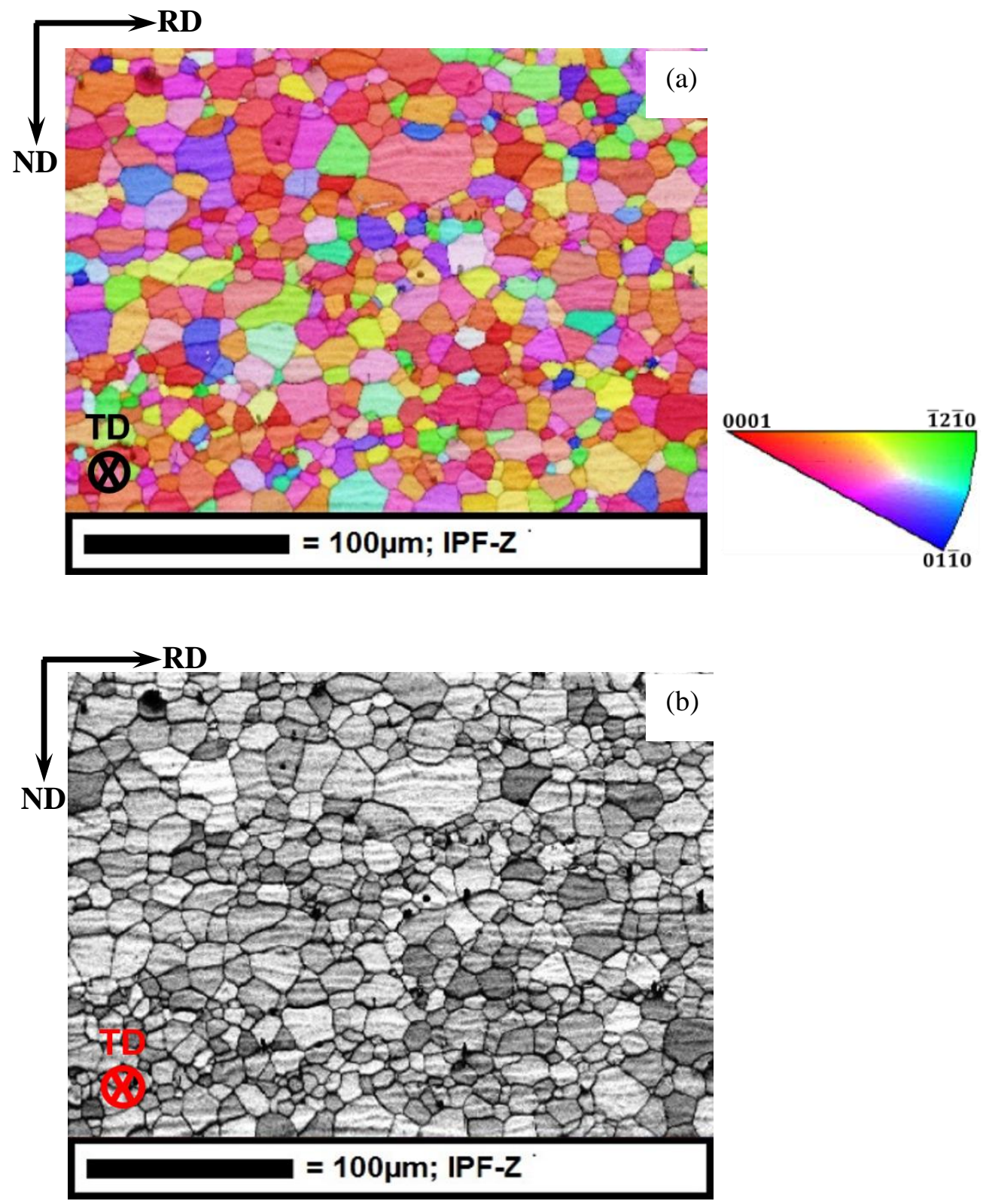

Fig.5 Normal-projected EBSD (a) orientation map of the rolled ZEK100 Mg alloy, (b) band contrast (BC) map of the rolled ZEK100 Mg alloy, where RD stands for the rolling direction and ND indicates the normal direction. 
The typical SEM back-scattered electron image of the rolled ZEK100 specimen was shown in Fig.6 and several white particles were present. One of the bigger particles was chosen to do further analysis.

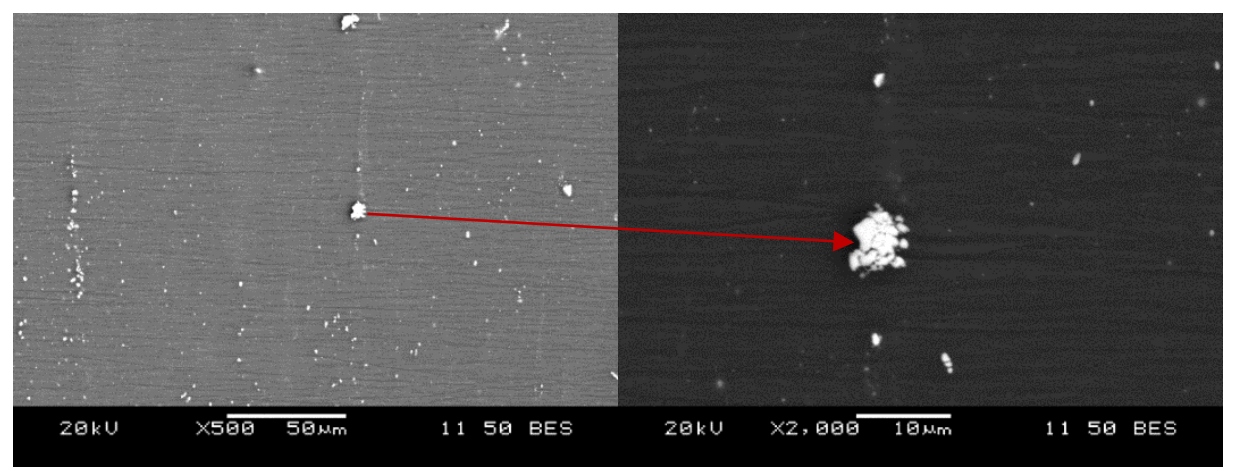

Fig.6 SEM back-scattered electron image

EDS line scan was done on the chosen particle and was shown in Fig.7. The EDS line scan results revealed that the white particle contains $\mathrm{Zn}, \mathrm{Nd}$, Fe metallic elements.
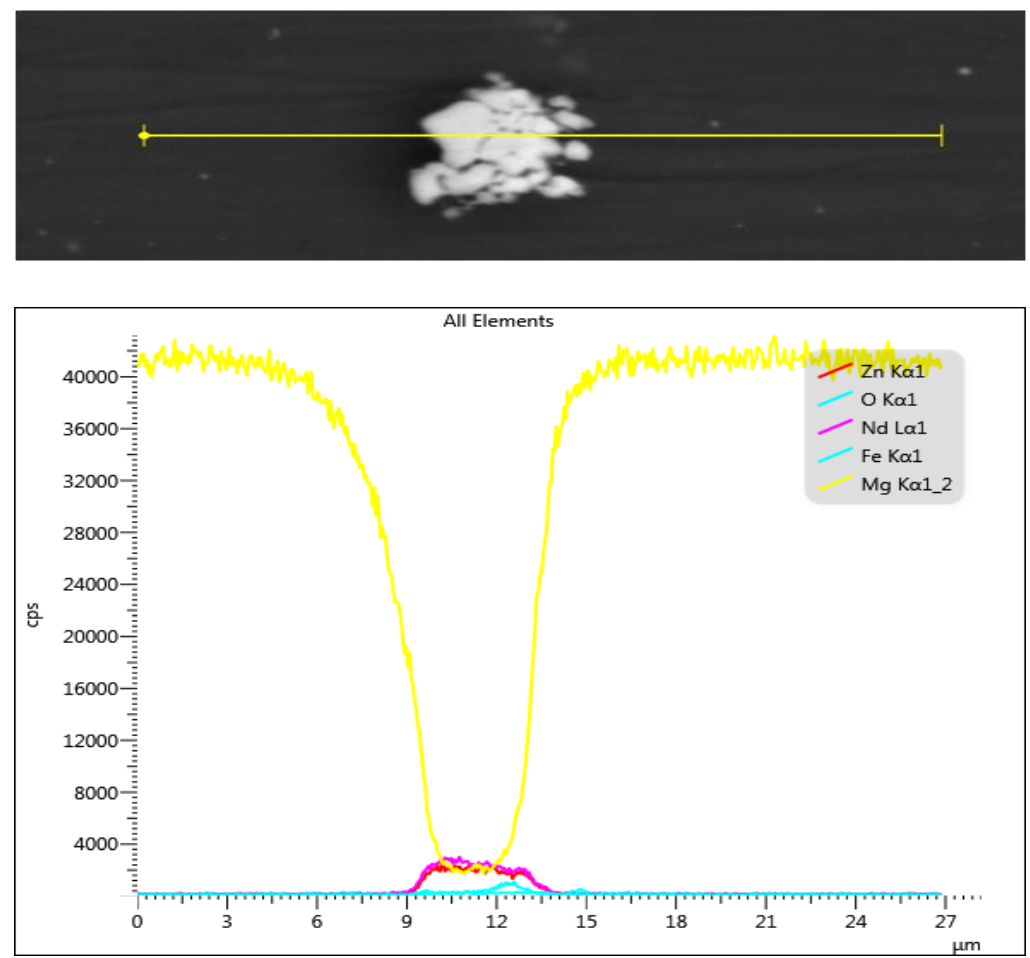

Fig.7 EDS line scan and Elements analysis 
Two points in the white particle were selected to do point scan and the results were shown in Fig.8. The result indicted that $\mathrm{Zn}$ and $\mathrm{Nd}$ were the major contained element in this particle. As studied in other researches[2,3,4], these $\mathrm{RE}$ and $\mathrm{Zr}$ containing particles could resist the grain growth and end of forming finer grains. During solidification process, in the liquid $\mathrm{Mg}$ alloy, the dissolved $\mathrm{Zr}$ could effectively limited the growth of nucleating $\mathrm{Mg}$ grains and led to refining the grains as well $[20,21]$.
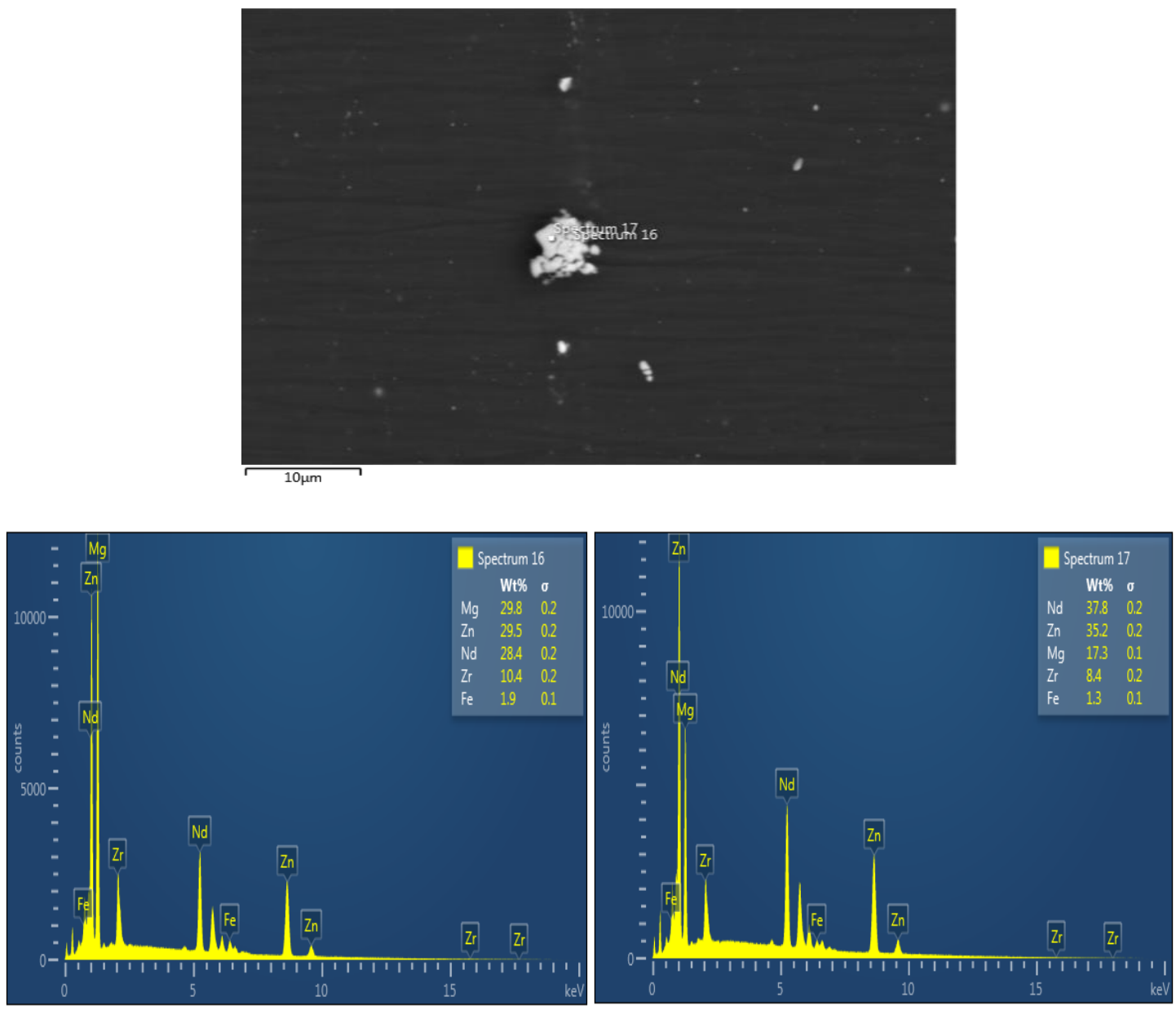

Fig.8 Point Scan of the ZEK100 Mg alloy 


\section{Crystallographic Texture}

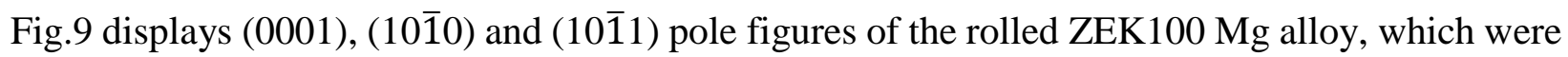
evaluated using the MTEX software. The analysis showed that the texture intensities were lower for ZEK100 than other RE-free Mg alloys. For example, the texture intensity of RE-free extrude AM30 alloy was 8.5 at multiples of random distribution(MRD) [22], while for the current ZEK100 the texture intensity of basal plane (where c-axes of most grains were perpendicular to the RD) was 3.43. It was clearly shown that compare with pure magnesium or other commercial Mg alloys the addition of $\mathrm{Nd}$ could cause texture weakening in ZEK100 alloy. Other searchers [23] also observed the decreasing pole intensities by adding RE element in Mg alloys. One reason for the texture weakening could be associated with formation of solid solution of RE element in Mg alloys, which increased the difficulty of rotation basal planes due to the different atomic radius of $\mathrm{Mg}$ and $\mathrm{RE}$ elements. Another reason for texture weakening was the formation of second phase precipitates like $\mathrm{MgZn}$ and $\mathrm{Mg}_{12} \mathrm{Nd}$ [2,3]. Some other researchers [24] showed that the precipitation of second -phase particles could delay the dislocation movement and form stress concentration close to the precipitates. This phenomenon could enhance the particle nucleation of dynamic recrystallization and lead to weakening of basal texture.

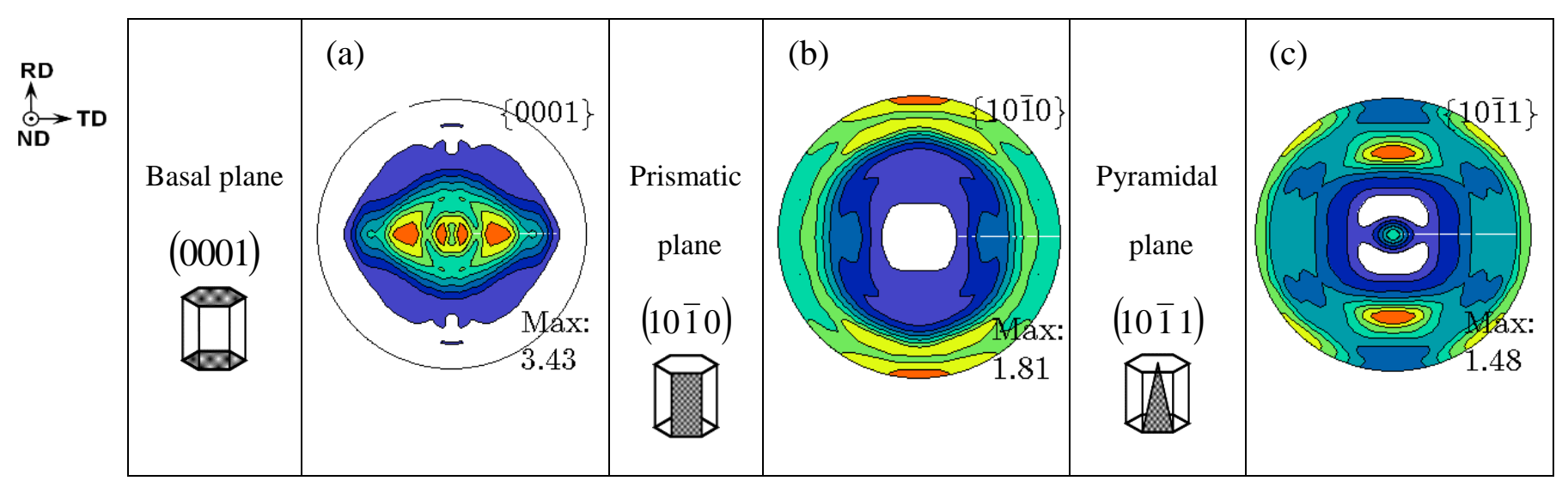

Fig. 9(0001), (1010) and (1011) pole figures of the rolled ZEK100 Mg alloy, where RD stands for the rolling direction, TD for the transverse direction, and ND for the normal direction. 
4 Tensile test

Tensile properties of ZEK100 were tested at strain rate of $1 \times 10^{-2} s^{-1}$ and $1 \times 10^{-2} s^{-4}$ at RT and the results were shown in Table 2. True stress versus true strain of 4 tested specimens were plot in Fig.10. It could be easily observed from Fig.10 that true strain increased with increasing true stress until failure, and the true stress increased with increasing strain rate.

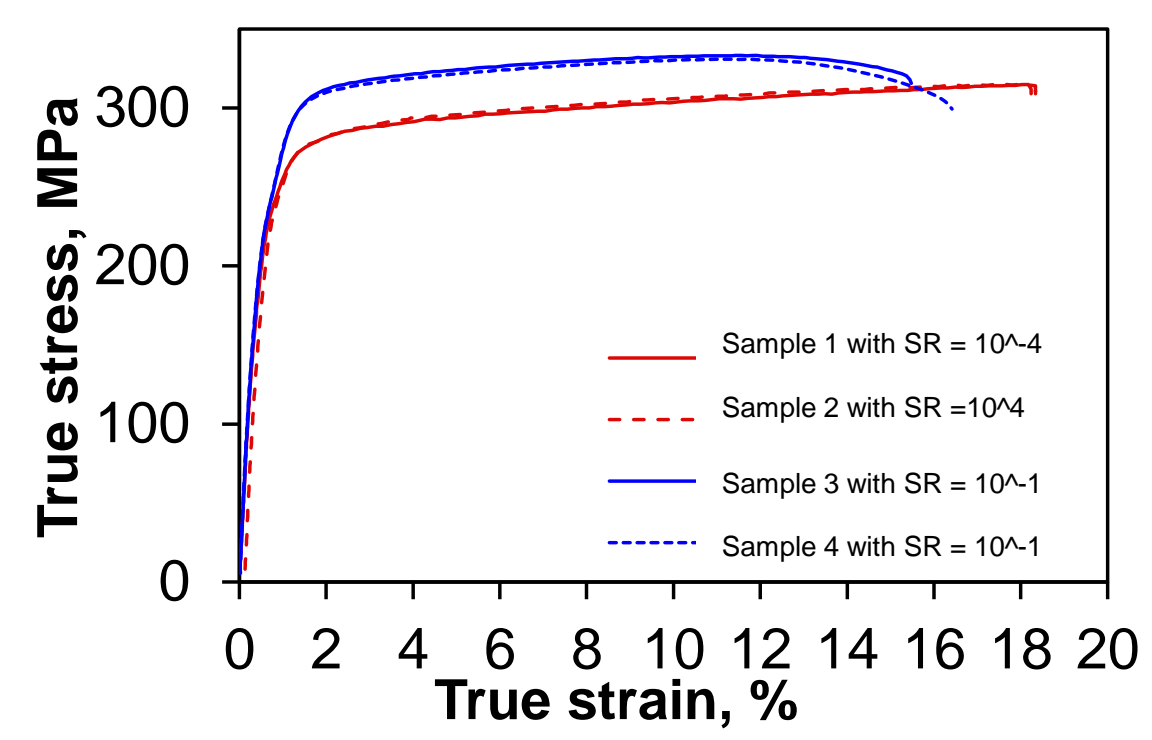

Fig.10 Relationship of true stress vs. true strain for ZEK100 under two strain rate.

The mechanical properties of ZEK100 alloys are summarized in Table 2 and ploted in Fig.11. With different strain rates, ZEK100 alloy had a tensile yield strength between 225-230MPa, which is in between extruded AM30 (200MPa [25]) and GW103K (240MPa [26]) alloys. The ultimate tensile strength of ZEK100 are between $315-335 \mathrm{MPa}$, which is close to that of GW103K Mg alloy (318MPa [27]) and GW123K Mg alloy (335MPa [28]). Higher equivalent elongation of 16.6\%$21.8 \%$ for ZEK100 alloy is noted in comparison with GW103K (8.3\% [3,25]), which indicates the higher ductility of ZEK100 alloy. Since compared with GW103K (high RE-containing Mg alloy) and AM30 (RE free alloys), ZEK100 with slight addition of Nd (0.2wt\% Nd), Zn (1.3wt\% Zn) 
and $\mathrm{Zr}(0.25 \mathrm{wt} \% \mathrm{Zr})$ clearly indicated that slight addition of RE element could effectively improve the tensile strength of $\mathrm{Mg}$ alloy.

Table 2 Tensile properties of ZEK100 alloys obtained at two different strain rate at room temperature

\begin{tabular}{cccccccc}
\hline ZEK100 & $\begin{array}{c}\text { Strain } \\
\text { Rate } \\
\left(\boldsymbol{s}^{-\mathbf{1}}\right)\end{array}$ & $\begin{array}{c}\boldsymbol{\sigma}_{Y S} \\
(\mathbf{M P a})\end{array}$ & $\begin{array}{c}\sigma_{U T S} \\
(\mathbf{M P a})\end{array}$ & $\begin{array}{c}\text { Elongation } \\
\mathbf{( \% )}\end{array}$ & $\mathbf{n}$ & $\boldsymbol{\sigma}_{U T S} / \sigma_{Y S}$ & $\begin{array}{c}\text { Hardening } \\
\text { Capacity }\end{array}$ \\
\hline $\begin{array}{c}\text { Sample } \\
\mathbf{1}\end{array}$ & $\begin{array}{c}1 \times \\
\mathbf{1 0}^{-\mathbf{1}}\end{array}$ & 229 & 333 & 16.6 & 0.18 & 1.46 & 0.4572 \\
\hline $\begin{array}{c}\text { Sample } \\
\mathbf{2}\end{array}$ & $\begin{array}{c}1 \times \\
\mathbf{1 0}^{-\mathbf{1}}\end{array}$ & 228 & 331 & 18.8 & 0.18 & 1.45 & 0.4525 \\
\hline $\begin{array}{c}\text { Sample } \\
\mathbf{3}\end{array}$ & $\begin{array}{c}1 \times \\
\mathbf{1 0}^{-4}\end{array}$ & 226 & 315 & 28.6 & 0.18 & 1.40 & 0.3954 \\
\hline $\begin{array}{c}\text { Sample } \\
\mathbf{4}\end{array}$ & $\begin{array}{c}1 \times \\
\mathbf{1 0}^{-4}\end{array}$ & 225 & 320 & 21.8 & 0.18 & 1.42 & 0.4218 \\
\hline
\end{tabular}

Fig.11 clearly showed that as strain rate increase, yield stress, ultimate tensile strength and hardening capacity increased, but the elongation decreased. This phenomenon indicated the strain rate could strongly influence tensile properties and the failure mechanism of ZEK100 Mg alloy.

(a)

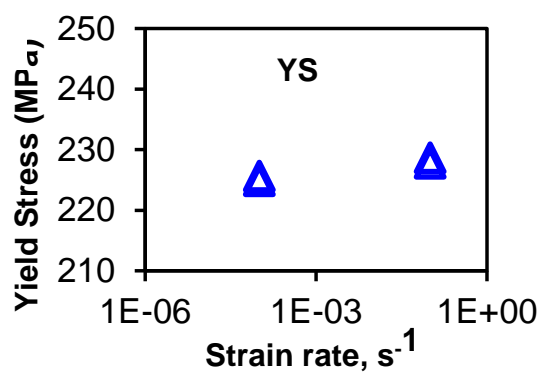

(c)

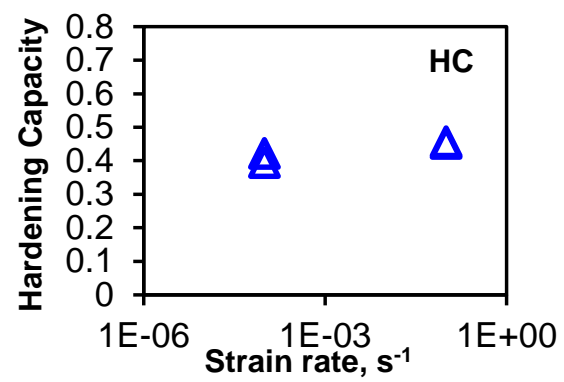

(b)

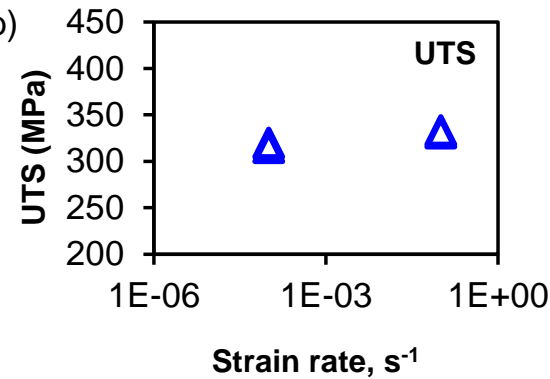

(d)

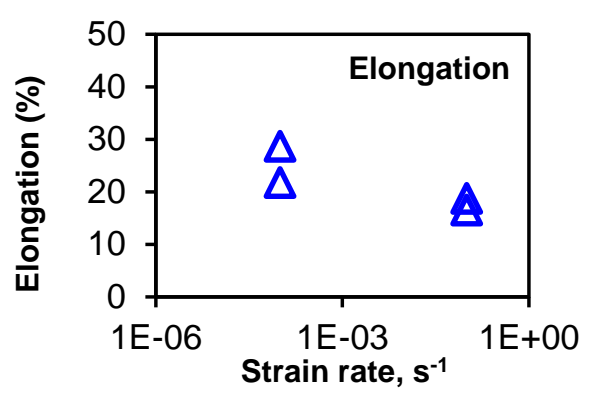

Fig 11. Mechanical properties of ZEK100 under strain rate of $1 \times 10^{-2} s^{-1}$ and $1 \times 10^{-2} s^{-4}:(a)$ Yield Stress; (b) Ultimate tensile strength; (c) Hardening capacity; (d) Elongation. 
5 Stress-controlled fatigue test

The stress controlled fatigue data is represented by stress-life curves which is the plot of stress against the number of cycles. The S-N curve could represent the examined fatigue characteristic of Mg alloys. Fig. 12 showed the S-N curve for ZEK100 Mg alloy in different stress ratios. The plot ran out data points at $10^{7}$ where no fatigue failure occurred. This plot show that as stress ratio increases, the stress amplitude and the fatigue life both decrease significantly. Other research of RE-containing Mg alloys showed the addition of RE elements could efficiently improve the fatigue strength of $\mathrm{Mg}$ alloys [4]. The grain size of $\mathrm{Mg}$ alloys was remarkably reigned due to the addition of RE elements [4]. This led to improvement of HCP properties of $\mathrm{Mg}$ alloy, because increasing grain boundaries could increase the resistance of dislocation movement during plastic deformation. Studies of other RE containing Mg alloy, such as Mg-12Gd-3Y-0.5Zr and Mg-19Gd-3Y showed similar strength improvement with the addition of RE elements [6,30]. Other research shows that heat treatment could significantly improve the fatigue life of RE containing Mg alloy [29].

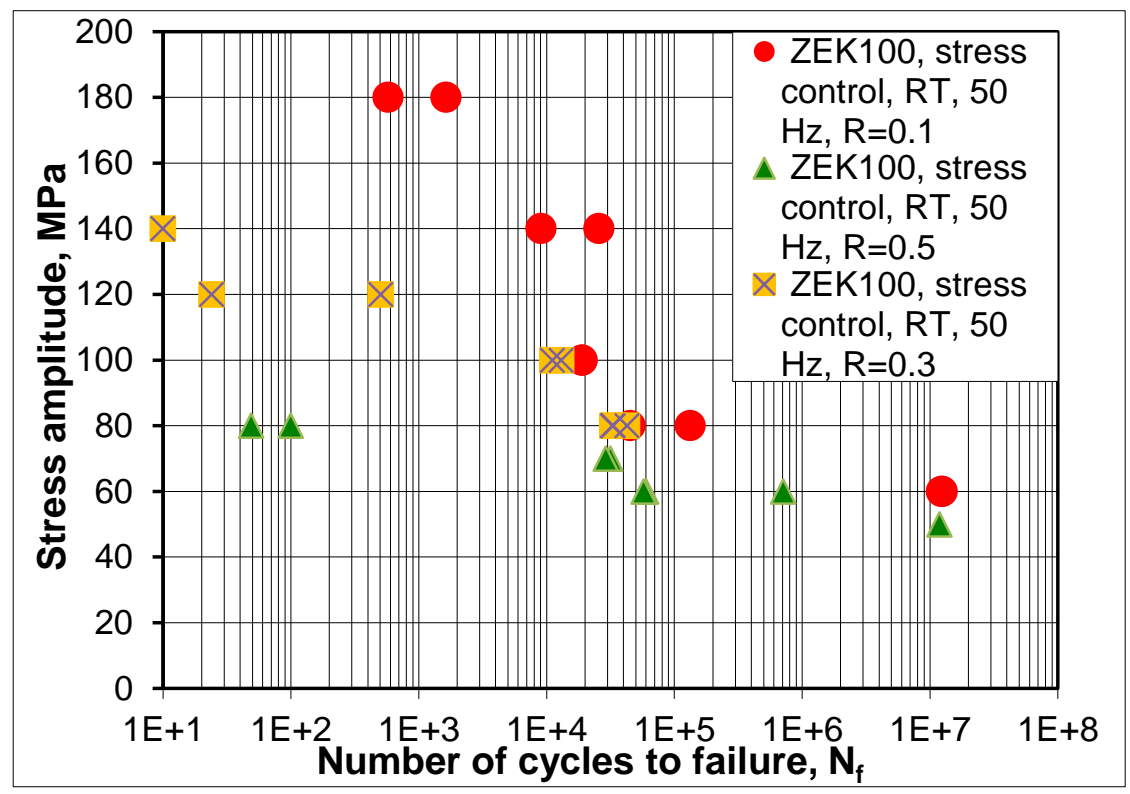

Fig.12 S-N curve for ZEK100 Mg alloy with different stress ratio. 
Another way of observing the fatigue behavior was through Coffin-Mason and Basquin's equation. Since the high-cycle stress control fatigue tests were did on ZEK100 alloys, Basquin's equation was used to analyze the fatigue parameters:

$$
\frac{\Delta \sigma}{2}=\sigma_{f}^{\prime}\left(2 N_{f}\right)^{b}
$$

where $N_{f}$ is the number of cycles to failure, $\sigma_{f}^{\prime}$ is the fatigue strength coefficient, $\mathrm{b}$ is the fatigue strength exponent. With the collected data from fatigue test, the values of $\sigma_{f}^{\prime}$ and $\mathrm{b}$ at different stress ratio were calculated and listed in Table 3:

Table 3 High cycle fatigue parameters obtained at different stress ratio for the rolled ZEK100 $\mathrm{Mg}$.

\begin{tabular}{ccc}
\hline Stress Ratio, $\mathbf{R}$ & $\begin{array}{c}\text { Fatigue strength } \\
\text { coefficient, } \boldsymbol{\sigma}^{\prime}{ }_{\boldsymbol{f}}(\mathbf{M P a})\end{array}$ & $\begin{array}{c}\text { Fatigue strength exponent, } \\
\mathbf{b}\end{array}$ \\
\hline $\mathrm{R}=0.1$ & 522 & -0.14 \\
\hline $\mathrm{R}=0.3$ & 221 & -0.08 \\
\hline $\mathrm{R}=0.5$ & 98 & -0.03
\end{tabular}

Table 3 clearly showed that as the value of stress ratio increases, the value of $\sigma_{f}^{\prime}$ decreased and the value of $b$ increased. This phenomenon showed the connection between stress ratio and fatigue properties for ZEK100 Mg alloy. Other research on strain controlled fatigue test of rolled ZEK100 alloys reported the value of ${\sigma^{\prime}}_{f}$ as $654(\mathrm{MPa})$ and $\mathrm{b}$ as -0.14 which are close to the $\sigma_{f}^{\prime}$ and b value under stress ratio of 0.1 [2]. 
6 Fractography

Study of fracture surface could help to understand the process of material failure. Fracture surface of $\mathrm{Mg}$ alloys usually contains three areas: initiation area, crack propagation area and fast crack area. For Mg alloys, fatigue cracks usually initiate at surface then propagate through the entire specimen to failure. Fig.13 display an overall view of fatigued samples tested at stress ratio of 0.5 and stress amplitude of 60MPa. As seen from Fig.13 (b), crack initiated from the specimen surface or near surface defects.

(a)

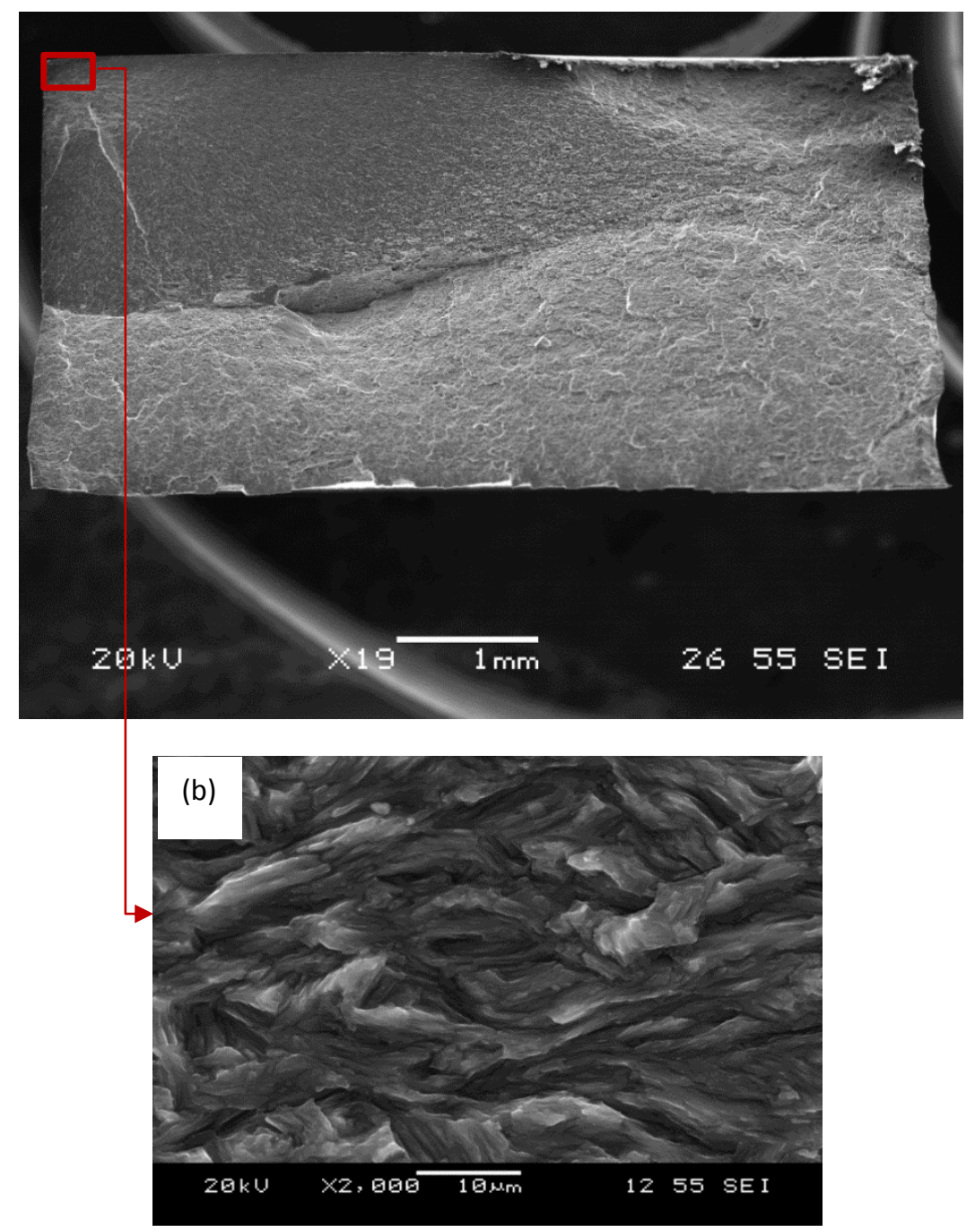

Fig 13. SEM Microstructure of overall fracture surface of the specimens fatigued at Stress ratio $R=0.5$, Stress amplitude 60MPa (a) overall fracture surface, (b) initiation area 
Similar to other metallic materials, fatigue fracture surface of $\mathrm{Mg}$ alloys consists of near threshold fatigue propagation. The SEM images take at higher magnification in the crack propagation area (Fig.14(a) and (4)) showed that at the fatigue crack propagation region encompassed some striation- like features which were the distinct line markings appeared on the fracture surface. Similar observations were reported in other papers [2,3,6-9]. Fatigue crack propagation region was characterized by fatigue striations, and striation- like features were also found to be perpendicular to the crack propagation direction. Few secondary cracks were also perceived in the crack propagation area which are shown in Fig.14(b).

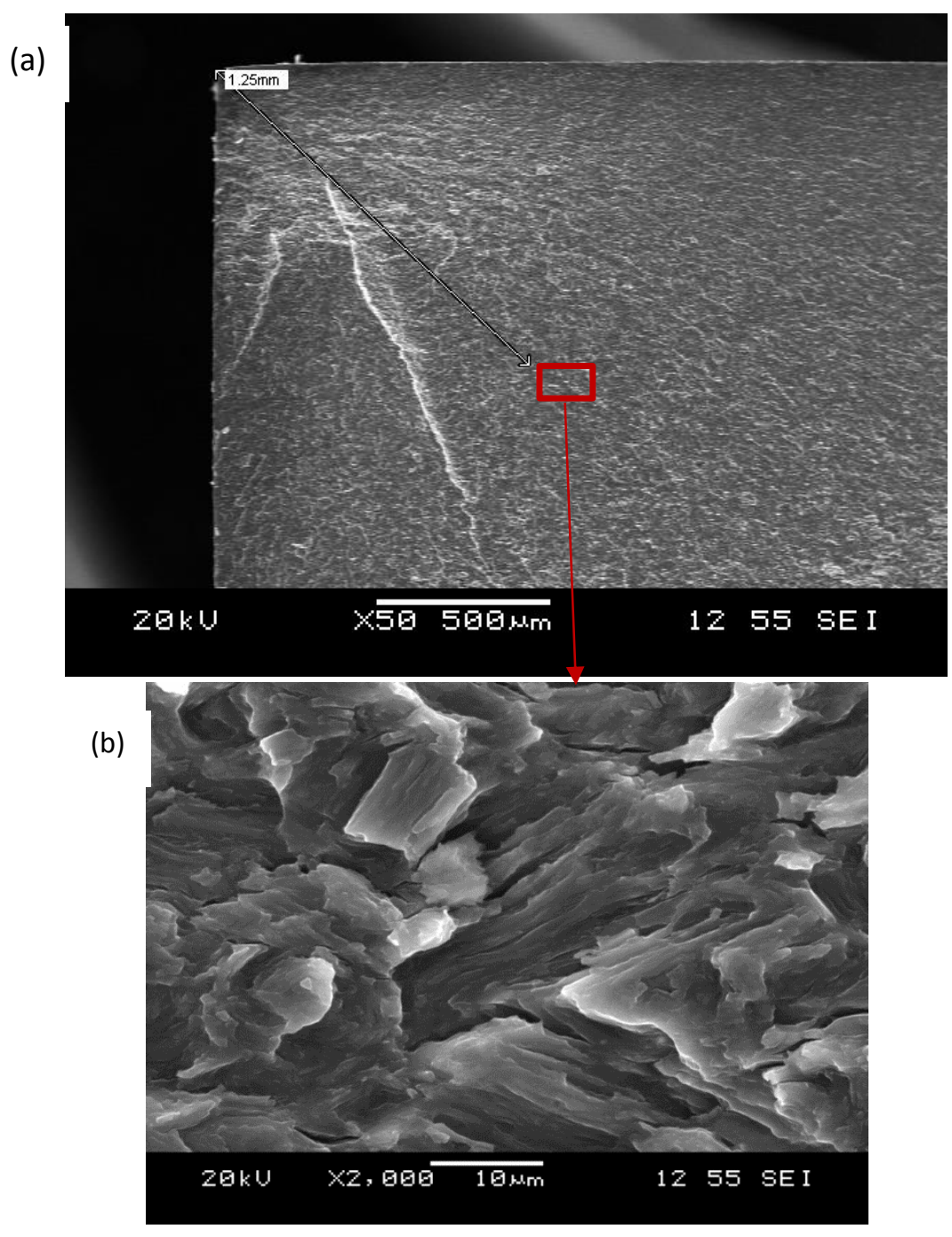

Fig 14. SEM Microstructure of overall fracture surface of the specimens fatigued at Stress ratio $R=0.5$, Stress amplitude 60MPa (a) overall fracture surface with slected crack propagation zone, (b)crack propagation area 
The biggest region of the overall fracture surface is the fast crack area which was shown in Fig. 15. Some shallow dimples could be seen from the fast crack area which were marked by red arrows in Fig.15. These dimple structure implies the existence of larger plastic deformation in the present ZEK100 Mg alloys. For specimens tested under larger stress amplitude, the fracture surface only showed the fast crack area which indicates that the failure is more similar to tensile test failure than it is to fatigue failure.

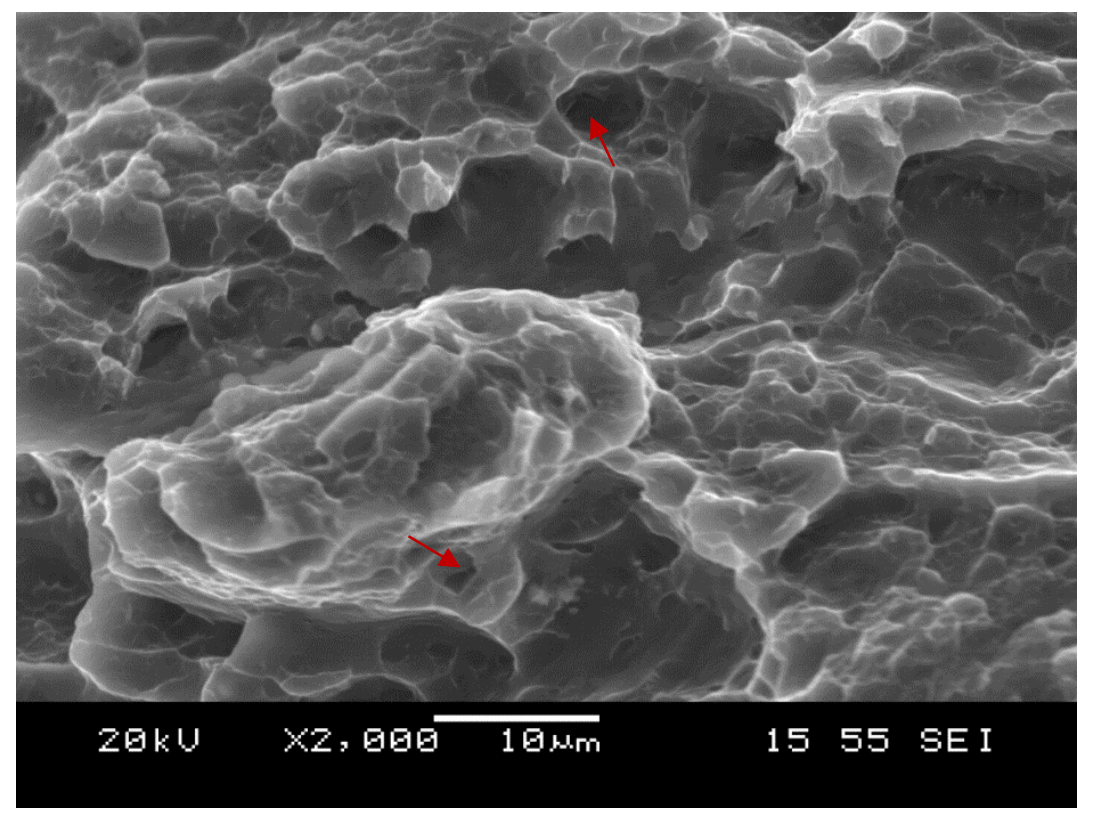

Fig 15. SEM Microstructure of fast crack area for Mg ZEK100 fatigued at Stress ratio R=0.5, Stress amplitude $60 \mathrm{MPa}$ 


\section{Conclusion}

The mechanical properties of rolled ZEK100 were studied. Microstructure and texture were analyzed. Tensile and stress controlled tests were performed on dog bone shape samples. The following conclusions can be drawn from this investigation:

1. The microstructure of ZEK100 alloys in the annealing state consisted of equiaxed grains and this phenomenon were due to dynamic recrystallization. ZEK100 alloy also observed to contained $\mathrm{MgZn}$ and $\mathrm{Mg}_{12} \mathrm{Nd}$ particles. The addition of $\mathrm{RE}$ elements is main reason caused the weakening of basal texture.

2. Tensile test showed that the true strain increased with increasing true stress, and the true stress increased with increasing strain rate. During the tensile test, as strain rate increased, yield stress, ultimate tensile strength and hardening capacity increased, but the elongation decreased. Strain rate could strongly influence tensile properties of ZEK100 Mg alloy.

3. The study of stress controlled fatigue test indicated as stress ratio increased, the stress amplitude and the fatigue life both decreased significantly. RE elements could efficiently improve the fatigue strength of $\mathrm{Mg}$ alloys. The grains size of $\mathrm{Mg}$ alloys was remarkably reigned due to the addition of RE elements and led to the improvement of HCP properties of ZEK100 alloys. In stress-controlled fatigue tests, as stress ratio increased, the value of $\sigma_{f}^{\prime}$ decreased and the value of $b$ increased.

4. Fatigue crack initiation was observed to occur from the surface of specimen. Some striationlike features were observed to appear at crack propagation region. Striation-like features were found to be perpendicular to the crack propagation direction. Some shallow dimples were found to be formed at fast crack area.

Since lack of knowledge of mechanical properties of ZEK100 under different heat treatment states, further studies of ZEK100 alloys could focus on comparing of fatigue behavior under elevated temperature. Since strain-controlled fatigue test could provide more information, strain-controlled fatigue test should be applied on ZEK100 alloys instead of stress controlled fatigue tests. Further study of twinning and detwinning mechanism could help to understand the fatigue failure process and how to improve tensile and fatigue strength of $\mathrm{Mg}$ alloys. Different concentrations of $\mathrm{RE}$ elements could lead to change of fatigue strength, therefore the study of adding different RE 
elements and different weight percentages could help lower the cost of producing RE-containing $\mathrm{Mg}$ alloys. 


\section{References}

[1] Min J, Lin J. Anelastic behavior and phenomenological modeling of Mg ZEK100-O alloy sheet under cyclic tensile loading-unloading[J]. Materials Science and Engineering: A, 2013, 561: 174182.

[2] Mokdad F, Chen D L. Strain-controlled low cycle fatigue properties of a rare-earth containing ZEK100 magnesium alloy[J]. Materials \& Design, 2015, 67: 436-447.

[3] Mokdad F, Chen D L. Cyclic deformation and anelastic behavior of ZEK100 magnesium alloy: effect of strain ratio[J]. Materials Science and Engineering: A, 2015, 640: 243-258.

[4] Mirza F A, Chen D L, Li D J, et al. Low cycle fatigue of a rare-earth containing extruded magnesium alloy[J]. Materials Science and Engineering: A, 2013, 575: 65-73.

[5] Mirza F A, Chen D L. Fatigue of rare- earth containing magnesium alloys: a review[J]. Fatigue \& Fracture of Engineering Materials \& Structures, 2014, 37(8): 831-853.

[6] Naiyi Li, Automotive magnesium applications and life cycle environmental assessment, 3rd International Conference on SF6 and the environment, Scottsdale, 2004.

[7] Wang, Jian, J. P. Hirth, and C. N. Tomé. "Twinning nucleation mechanisms in hexagonalclose-packed crystals." Acta Materialia 57.18 (2009): 5521-5530.

[8] Begum S, Chen D L, Xu S, et al. Low cycle fatigue properties of an extruded AZ31 magnesium alloy[J]. International Journal of Fatigue, 2009, 31(4): 726-735.

[9] B.L. Mordike and T. Ebert, Magnesium properties-applications-potential, Materials Science and Engineering A, 2001, Vol. 302, pp37-45.

[10] Xu, D. K., and E. H. Han. "Relationship between fatigue crack initiation and activated twins in as-extruded pure magnesium." Scripta Materialia 69.9 (2013): 702-705.

[11] Beyerlein, I. J., R. J. McCabe, and C. N. Tomé. "Effect of microstructure on the nucleation of deformation twins in polycrystalline high-purity magnesium: A multi-scale modeling study." Journal of the Mechanics and Physics of Solids, 59.5 (2011): 988-1003. 
[12] He, J. J., et al. "Deformation behaviour of hot extruded Mg alloy AZ31 during compressive deformation." Materials Science and Technology 29.2 (2013): 177-183.

[13] Xu, D. K., and E. H. Han. "Relationship between fatigue crack initiation and activated twins in as-extruded pure magnesium." Scripta Materialia 69.9 (2013): 702-705.

[14] Antoniswamy A R, Carpenter A J, Carter J T, et al. Forming-limit diagrams for magnesium AZ31B and ZEK100 alloy sheets at elevated temperatures[J]. Journal of materials engineering and performance, 2013, 22(11): 3389-3397.

[15] Min J, Lin J, Li J. Forming limits of Mg alloy ZEK100 sheet in preform annealing process. Mater Des 2014;53:947-53.

[16] Lin XZ, Chen DL. Strain controlled cyclic deformation behavior of an extruded magnesium alloy. Mater Sci Eng, A 2008;496:106“C13.

[17] F.Bachmann,F.R.Hielscher,H.Schaeben,SolidStatePhenom.160(2010) 63-68.

[18] K. Hantzsche,J.Wendt,K.U.Kainer,J.Bohlen,D.Letzig,JOM61(2009)38-42.

[19] N. Stanford,M.R.Barnett,Mater.Sci.Eng.A496(2008)399-408.

[20] Arroyave R, Shin D, Liu ZK. Modification of the thermodynamic model for the Mg-Zr system. CALPHAD 2005;29:230-8.

[21] Lee YC, Dahle AK, St John DH. The role of solute in grain refinement of magnesium. Metall Mater Trans A 2000;31:2895-906.

[22] D. Sarker,D.L.Chen,Mater.Sci.Eng.A582(2013)63“C67.

[23] N. Stanford,D.Atwell,M.R.Barnett,ActaMater.58(2010)6773-6783.

[24] F.J.Humphreys,ActaMater.45(1997)5031-5039.

[25] S. Begum,D.L.Chen,S.Xu,A.A.Luo,Metall.Mater.Trans.A39(2008) 
3014-3026.

[26] F.A.Mirza,D.L.Chen,D.J.Li,X.Q.Zeng,Mater.Sci.Eng.A575(2013)65-73.

[27] F.A.Mirza,D.L.Chen,D.J.Li,X.Q.Zeng,Mater.Sci.Eng.A588(2013)250-259.

[28] F.Yang,F.Lv,X.M.Yang,S.X.Li,Z.F.Zhang,Q.D.Wang,Mater.Sci.Eng.A528

(2011)2231-2238.

[29] Yang, Y. and Liu, Y. B. (2008) High cycle fatigue characterization of two die-cast magnesium alloys. Mater Charact, 59, 567-570.

[30] Mokhtarishirazabad, M., Boutorabi, S. M. A., Azadi, M. and Nikravan, M. (2013) Effect of rare earth elements on high cycle fatigue behavior of AZ91 alloy.Mater. Sci. Eng. A, 587, 179184. 